\title{
A Discussion on the Scientific Management of Examination in Colleges and Universities
}

\author{
Runxiang $\mathrm{Xu}^{1, *}$ Mingzhu $\mathrm{Li}^{2}$ \\ ${ }^{1}$ College of Economics and Management, Weifang University, Weifang, Shandong 261061, China \\ ${ }^{2}$ College of Foreign Languages, Inner Mongolia Agricultural University, Huhhot, Inner Mongolia 010018, China \\ *Corresponding author.Email: cyxrx@126.com
}

\begin{abstract}
Examination is the test of teaching quality, while management is the core to determine the quality. The examination management in colleges and universities must be connected with the teaching quality and students' comprehensive quality, so that the examination can comprehensively examine the students' academic construction. In today's society, the ever-increasing demand for innovative and entrepreneurial talents promotes the continuous reform and innovation of teaching in colleges and universities, and the original examination management faces many challenges. This article analyzes the existing problems in the current examination management of colleges and universities, and specifically discusses the formulation of a scientific examination management system in colleges and universities in order to achieve the goal of improving the quality of teaching and the overall quality of students.
\end{abstract}

Keywords: colleges and universities, examination, management, scientization

\section{INTRODUCTION}

As an important part of the teaching process in colleges and universities, the examination has the functions of integrating, checking, evaluating, supervising, feedback, and motivating students' knowledge. It is also an indispensable teaching method to test the teaching level and teaching effect of teachers, and the quality of examination management. It is directly related to the teaching quality of colleges and universities and the comprehensive quality of students. At present, in order to meet the social demand for innovative and entrepreneurial talents, colleges and universities have innovated and reformed teaching. The traditional teaching model can no longer adapt to the development of colleges and universities, and the original examination management will inevitably have many problems.[1] This requires colleges and universities to take targeted measures to scientifically manage exams and gradually establish a peopleoriented, scientific and standardized college exam management system through continuous reform and improvement to promote teaching by exams and guide learning by exams so as to create a fair and just competition environment for students. In this way the purpose of improving the quality of teaching and improving the overall quality of students can be achieved.

\section{Problems existing In CURRent COLLEGE EXAMINATION MANAGEMENT}

\section{A. Cognitive bias of examination function}

As far as the current situation is concerned, the course examinations in colleges and universities are a sign of teachers' completion of teaching tasks, and also a means for students to obtain scores at the end of the course. Under the dual pressure of social competition and the employment of multinational talents, academic performance has become the key to judging students' abilities and qualities and affecting their further studies. This has led to a vicious circle of students one-sidedly pursuing high course scores, neglecting knowledge and ability training, being eager for quick success and learning for exams. Some students get a diploma as the ultimate goal of learning, so they often hear the slogan "Long live the pass". Competing for rankings, getting rewards, and earning credits are the purposes of student examinations. Obviously, the purpose of the test has been distorted in reality, and the deviation and limitations of the test function positioning make the students' test-taking ability one-sidedly strengthened, and their personality and cognition tend to be uniform. The one-sidedness of the examination function intensifies the utilitarianization of the purpose of the examination, which leads to the decrease of the examination's utility and the alienation of the teaching function. Teaching mainly serves examinations. Teachers teach for examinations and students learn for examinations. Both the teaching methods of teachers 
and the learning methods of students are obviously affected and restricted by examinations. Investigating the reason, it can be found that the problem is mainly due to the deviation of the functional cognition of the test. The values of deliberately emphasizing the scores leads to the phenomenon of "valuing evaluation and neglecting orientation" which is widespread in Chinese universities. Teachers often only attach importance to performance evaluation. After completing the marking and marking, handing over the results to the academic affairs department means the end of the work of the semester. Even if some teachers analyze the test papers, they only make approximate statistics on the passing rate, failing rate, and excellent rate, sorting the rankings and counting the number of students in each score section, and do not seriously and scientifically analyze the existence of the test paper. The problem is that the final result is only to inform students of their grades. In the later stage, they did not provide timely feedback on the students' lack of knowledge and abilities. The examination's diagnostic and feedback functions for teaching are not effectively reflected, which is not conducive to teaching reflection, adjustment of teaching content and improvement of teaching quality.

\section{B. Inefficient system of exams}

The present system of college exams includes the mid-term exam, final exam and all kinds of complementary exams for the students who fail to pass the final. Regarding the problem of failing the exam, the common practice of all universities is: at the beginning of each semester, students who do not meet the exam requirements in the final exam of the last semester will be organized to make a make-up exam, which is the examination for the same course. Those who have passed the re-examination and retake will be listed in the transcript according to the pass grade. The initial purpose of make-up exams and retakes is to give students one more chance to take the exam, but compared with normal exams, the requirements for make-up exams and postponement exams are often too low and the standards are lowered. From the difficulty of the test questions, to the invigilation, and the marking and grading are not as strict as the normal test, even if the students do not review carefully, they can easily pass, and the make-up test becomes a formality. Some students even take advantage of the loopholes and apply for postponement for fear of failing the normal exam.[2-3] The existence of this kind of examination makes the formal examination useless, which is not consistent with the original intention when the make-up examination was set up.

\section{The form and content of the course examination are too single}

Currently, most of the course examinations in colleges and universities present commonalities, that is, more closed-book exams, fewer open-book exams, more theoretical exams, less skills exams, more written exams, less oral exams, more unified exams, fewer small exams, more end-of-course exams, and fewer mid-term exams. Most of the content of the course test is based on the teacher's teaching content, with more objective knowledge assessment and less subjective knowledge application. Therefore, the test content is too single and rigid, and it is difficult to reflect the characteristics of the course. Memorization and derivation of pure knowledge cannot examine students' comprehensive qualities, creativity, practice, and thinking abilities. Moreover, under the mode of "teaching and examination in one", the work of teaching, proposition, marking and grading is all completed by the individual teachers. Teachers' teaching behavior is difficult to be restrained by the curriculum syllabus, and it often occurs that teachers take the examination of whatever they teach, making the curriculum syllabus useless. Most students, to varying degrees, do not study hard at ordinary times, copy homework, and ask teachers to focus on review before the test, define the scope or reduce the difficulty of the test.[4]

\section{The score evaluation lacks scientificity}

Although many colleges and universities have adjusted their performance evaluation system, abandoning the practice of one-time final exams and incorporating students' daily scores into the course performance evaluation assessment, but the evaluation indicators of daily scores, the weight selection of usual scores and final scores still lack corresponding scientifically theoretical support. Most colleges and universities judge their usual grades based on class attendance or a coursework. Their settings lack creativity and scientificity, and they also lack uniform standards. Some teachers randomly give a daily score and then set the score after a closed-book test. Irregular behaviors in the examination are detrimental to the cultivation of diverse talents and the cultivation and selection of talents at different levels.[2], [5]

At present, colleges and universities still generally do not pay enough attention to the management of paper marking. After the course examination is over, some teachers in the class are often reviewed at home. The centralized marking is mostly a formality. The school lacks effective supervision and it is easy to give favors to individual teachers. The phenomenon of scoring makes the test scores lose their due objectivity, fairness and seriousness and encourages students' laziness and speculation, which is not conducive to the formation of an honest world outlook and values, and is not conducive to the formation of a good style of study.[6] 


\section{TO BUILD A SYSTEMATIC, SCIENTIFIC AND RATIONAL EXAMINATION MANAGEMENT SYSTEM}

\section{A. To establish and improve the relevant examination management system}

Efficient and standardized examination management system provides guiding principles and working foundation for scientific examination management, which is a necessary condition for the smooth progress of examinations. First of all, colleges and universities must first improve their understanding of examination management. When formulating relevant systems, they should combine the characteristics of different disciplines to ensure scientificity and reflect humanity. A scientific, reasonable, and innovative examination mode is conducive to improving the quality of teaching, cultivating students' creativity and independent learning ability, and achieving the interaction and mutual progress of teaching and learning. Second, relevant institutions should improve the test paper proposition, printing process, and confidentiality system. Thirdly, the officials in charge of organizing exams should set standard rules of the test organization, concerning the review of test paper, scoring, and the procedures of score entry. Fourthly, a new examination paper analysis system should be developed and researched in order to strengthen the feedback of examination results. In addition, the regulations on dealing with violations in examinations should be clarified explicitly and made known to all the faculty and students so as to effectively curb examination cheating. In order to effectively test students' learning achievement and achieve the ultimate goal of exam, a comparatively perfect system can render examination management scientific and standard.

\section{B. To train and build high-quality examination management team}

The establishment of a standardized examination system only provides guiding principles and work foundation for scientific examination management, and effective scientific management is implemented in the examination process. Therefore, the implementation of scientific guidance and control is the key to scientific examination management. In examination management, we must first strengthen organization and leadership and establish a savvy and capable examination management team. Examination staff is an important part of the examination management team, which involves the smooth development of various functional activities of examination management and the smooth realization of examination management objectives. Examination staff not only need to be familiar with various procedures and regulations related to examination work, but also proficient in using computers and various platform software. Only by creating an excellent examination management team can some internal rules and regulations and examination disciplines really play a role and produce practical results, so as to effectively ensure the smooth development of examination management.[7]

A capable examination management team not only refers to examination personnel, but also scientific research personnel. Practice has proved that if you want to have a successful exam practice, one must have scientific exam theory as a guide, especially in the current teaching management, one should integrate scientific management skills, advanced management theory and rich management experience into the exam management. The following four methods can serve as a guide to establish management team. Initially, carry out targeted research. Then, find ways to effectively improve the effectiveness of exam management. Thirdly, train teachers' capability of evaluating, sorting, and summarizing exams. Finally, detailed analysis of statistics and data based on grades, majors, and academic systems should be carefully made. These feedback results are not only conducive to teaching departments to improve teaching quality, will also help the student management department adjust the focus of student work and establish a good style of study.[2], [3]

\section{To establish scientific question banks and separate teaching from examination}

The establishment of the test question bank is not only for the benefit of teachers, it is also in the interest of students. As for the teachers, it is helpful to implement the separation of teaching from examination, to enhance teachers' sense of responsibility in teaching, to avoid the randomness of teachers' lectures, to encourage students to fully grasp knowledge, and to ensure the fairness of examinations. Furthermore, it can fairly and objectively reflect students' learning conditions, stimulate students' learning enthusiasm and sense of competition, build a good learning atmosphere, and prevent teachers from leaking exam-related questions before exams. Thus the establishment of it can promote both teaching and learning. Ensuring the quality, fairness and rigor of the test question bank is the key to this work. A high-quality test not only depends on the quality of the test questions, but also depends on the teacher's understanding of various types of questions and the reasonable combination of different test questions. This requires the teacher to have a higher ability to integrate and use the test paper. The propositions need to be carefully organized and reviewed by the directors of the teaching and research section of each specialty, and the dean of the school (department) strictly controls, strictly in accordance with the syllabus of the course, reasonably formulates the course examination standards, scientifically grasps the qualification standards of the examination, and determines the type of questions and their proportions. 
Difficulty and score distribution, etc., guide students to comprehensively and accurately understand, master and apply the knowledge they have learned in accordance with the major and course requirements. After completion, they will be stored in the school's electronic question bank and managed by the Academic Affairs Office. Before the exam, the teaching and research section discusses and determines the type, volume and score of each course, and uses the content as a unit from the school's question bank to prepare the test papers with a microcomputer. In order to ensure that the teaching keeps pace with the times, the various question banks in the question bank must reflect the latest teaching content in a timely manner. With the changes in the society's demand for talents, the revision of talent training plans, the replacement of teaching materials, etc., the test questions in the question bank must be Corresponding modifications and additions.[1], [3]

\section{To reform the curriculum examination format and implement the concept of whole examination}

The assessment method depends on the course syllabus. After locating the training plan for each major, when the teaching and research section discusses, researches, compiles, and determines the syllabus, it should determine the examination form of the course. It is not impossible to teach each one, and each test has its own. Because the nature of many courses in the professional setting is inconsistent, the training requirements are different, and the assessment methods can be completely different. It is not a generalization. One feasible way is to try to enrich the assessment forms. For example, subjects with strong practicality can be assessed by a combination of theory and practice. News courses are mostly assessed by simulated speeches, interviews, shooting, and writing essays. Computer information technology courses use advanced methods. more attention should be paid to usual performance as for computer-based exams and art courses, and the final grade is closely linked to usual performance.

The concept of the whole process of examinations should be carried out, and the daily assessment of students should be strengthened. This is not to let the school take exams every day, but to say that in the teaching process, teachers should understand the students' acquisition of knowledge through questions, dialogues, assignments, discussions, and quizzes according to the teaching content and key points of different stages. Appropriate increase of the proportion of usual grades in the general evaluation should be considered and implemented in teaching, which can deliberately guide students to focus on the learning process and daily accumulation, and continuous and effective learning can be truly achieved in this way.
Another effective measure is to design and make the network test operation program to realize intelligent question bank proposition. The form of the test questions will be more scientific, and the test will bid farewell to paper and pen, and will be completed directly on the computer. Large-scale exams that use the same test paper at the same time and at the same place will also be "smashed into parts". According to the needs of the candidates, the test will be selected on demand, beyond time and space, and it can also increase test opportunities, with great flexibility. In order to ensure a fair and competitive test environment, in addition to strengthening the management of all aspects of the test, it is also necessary to adopt corresponding high-tech anti-fraud measures, such as mobile phone signal shielding devices, electronic monitoring, invisible headset detectors, ID card recognizers, etc. Protective equipment to effectively eliminate exam fraud.[7], [8]

\section{CONCLUSION}

The core of the test is to supervise and guide students to review, consolidate, and selectively use, fully mobilize their subjective initiative and creativity; and test management is the key to ensuring the fair, just and effective development of the test. College examination management is a systematic, complex, and long-term task, involving a wide range of areas and heavy responsibilities. It requires all faculty and staff to work together and manage together to make it more scientific, standardized, rational, and humanized, and thus comprehensive Improve the quality of college education and teaching, promote the continuous advancement of education, and cultivate more innovative and high-quality talents for the society.

\section{References}

[1] Tian Zhenhan. Analysis of the problems existing in college examination management and improvement measures [J].Modernization of Education, 2018 (S4) :54-55

[2] Jiang tao. Scientific and standardized examination management in colleges and universities [J]. Journal of hubei correspondence university,2015,28(22):11-12.

[3] Nie Ying. Exploration of College Examination Reform under credit System [J]. Educational Exploration, 2014(10): 56-59.

[4] Hu Zhen-en. Current Situation and Countermeasures of College Examination Management [J]. Management and Technology of Small and Medium-sized Enterprises (The ten-day issue),2009(02):54

[5] Wang Xingzhi. Exploration on the realization of scientific and standardized examination management system in colleges and universities $[\mathrm{J}]$.Research and practice of innovation and entrepreneurship theory, 2019, 2(09): 152-153.

[6] Liang Xiaoling, XieDonghai, Zhu Chuanqu.On curriculum Examination and Examination Management Innovation in Colleges and Universities [J]. Contemporary Education Theory and Practice, 2010, 2 (04) :59-61. 
[7] Li Qingquan, BaoHongguang.On the Scientific Management of Educational Examinations in General Colleges and Universities[J] Journal of Hunan University of Science and Technology, 2008(08): 216-218.

[8] Liao Yingchun. Administer the examination according to law, and strengthen the scientific and humanized management of college curriculum examination [J]. Human Resource Management, 2010(04): 191+193. 